\title{
THYMOLIPOMA: A RARE, LARGE ANTERIOR MEDIASTINAL MASS
}

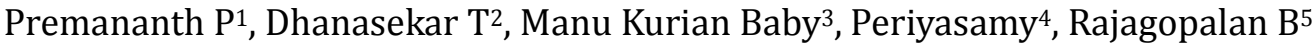

\section{HOW TO CITE THIS ARTICLE:}

Premananth P, Dhanasekar T, Manu Kurian Baby, Periyasamy, Rajagopalan B. "Thymolipoma: A Rare, Large Anterior Mediastinal Mass". Journal of Evolution of Medical and Dental Sciences 2015; Vol. 4, Issue 60, July 27; Page: 10556-10561, DOI: $10.14260 /$ jemds/2015/1522

ABSTRACT: Thymolipoma is a rare benign tumor of anterior mediastinum, described by Lange in 1916. ${ }^{1}$ Less than 200 cases have been reported worldwide. ${ }^{2}$ It accounts for $2 \%$ to $9 \%$ of thymic tumours. ${ }^{3}$ We report a case of thymolipoma in a 37 years old male patient, who presented with cough, dyspnea, chest pain for 2 months. CT THORAX revealed a large anterior mediastinal mass extending in to right hemithorax arising from thymus gland, with multiple areas of fat density, no significant mediastinal adenopathy, complete collapse of right middle and lower lobe suggestive of thymolipoma. CT guided biopsy suggestive of thymic neoplasm. The tumour was removed enbloc through surgery. Histopathological examination of large mass lesion confirmed thymolipoma. We report this case to emphasize the importance of considering thymolipoma as a differential diagnosis of anterior mediastinal mass, although rare.

KEYWORDS: Thymolipoma, Mediastinum, Thymus, histopathological, neoplasm.

INTRODUCTION: Thymolipoma is a rare, benign neoplasm of the thymus composed of mature adipose tissue and thymic tissue.

Most patients with thymolipoma are asymptomatic, local nonspecific symptoms may present or the tumour may be associated with parathymic syndromes such as myasthenia gravis, hyperthyroidism, lymphangiomas, aplastic anemia, chronic lymphocytic leukemia and hodkins disease. ${ }^{4}$ Most thymolipomas run an indolent course, often achieving massive dimensions before presentation. Thymolipomas can achieve massive dimensions-the largest paediatric and adult tumours weighed $2235 \mathrm{~g}^{5}$ and 6000 g respectively. ${ }^{6}$

Pre-operative diagnosis is the norm with well described CT and MRI features, and typical findings include the presence of a well-demarcated anterior mediastinal fatty mass containing islands and strands of soft tissue, which are pathognomonic features. ${ }^{7}$ Complete surgical excision is curative.

CASE REPORT: 37 years male presented to pulmonology outpatient department of Sri Ramachandra Medical College with complaints of cough, breathlessness, right sided chest pain for 2 months. Cough was nonproductive, Dyspnea insidious in onset, started as grade 1 MMRC (Modified medical research council) progressed to grade 4 MMRC over 2 months. Chest pain present over right posterolateral chest wall, dull and diffuse, no h/o radiation. No history suggestive of hemoptysis, wheeze, palpitation, syncope.

He was a farmer by occupation. No substance abuse. General physical examination was normal. Respiratory system examination revealed reduced movements on the right side, dull on percussion and absent breath sounds.

Chest radiograph showed a dense homogenous opacity in the right side. 


\section{CASE REPORT}

Fig. 1: Chest X-ray shows homogenous opacity in right hemithorax.

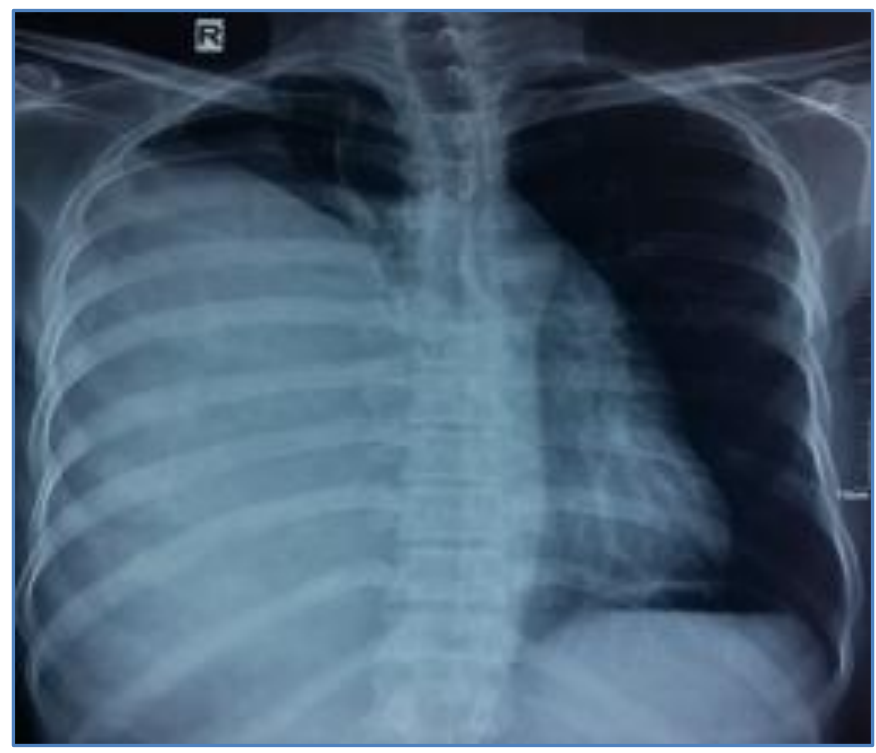

\section{Fig. 1}

USG Thorax study showed no evidence of pleural fluid.

Fig. 2: Usg thorax did not show any evidence of pleural effusion

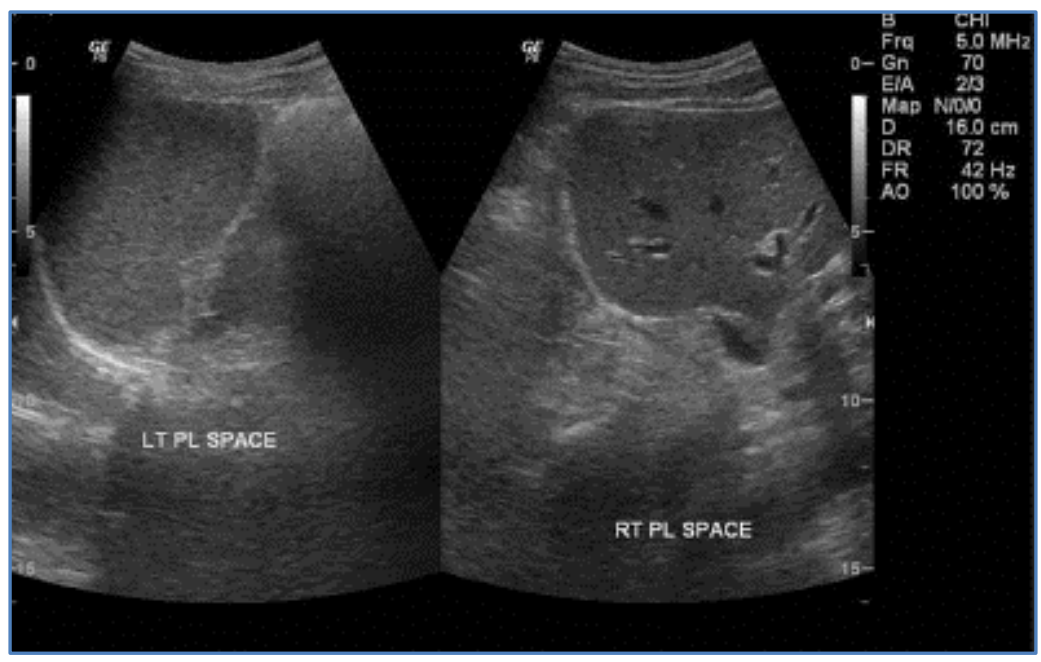

\section{Fig. 2}

Ct thorax study showed a large non-enhancing intrathoracic fat containing mass lesion (HU ranging from -71 to -102 ) is seen in the right hemithorax arising from thymus causing displacement of trachea, oesophagus and heart to left side, with mild herniation in to contralateral hemithorax, On administration of intravenous contrast, lesion does not show significant enhancement, no significant mediastinal adenopathy, complete collapse of right middle and lower lobe. Above findings suggestive of thymolipoma 


\section{CASE REPORT}

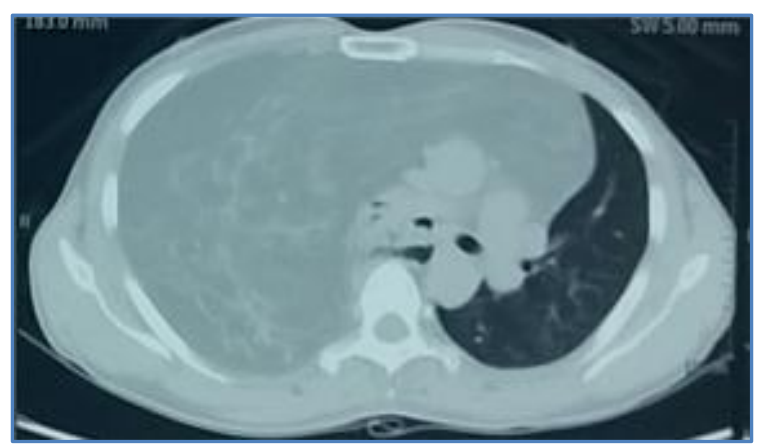

Fig. 3

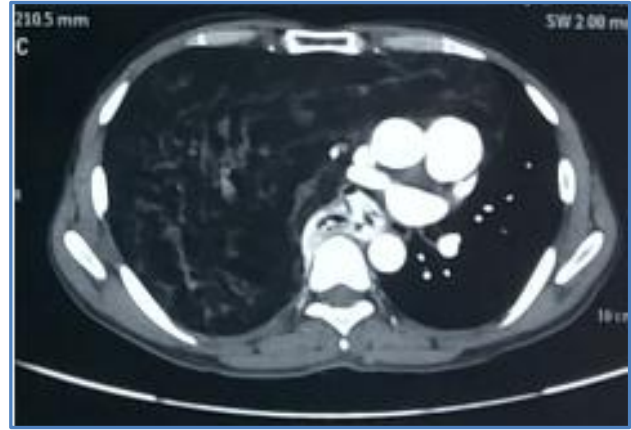

Fig. 4

Fig. 3 \& 4: Ct Thorax-lung window shows intrathoracic fat containing lesion in right side extending in to contralateral hemithorax.

Bronchoscopy study revealed extraneous compression of right bronchus intermedius.

CT guided biopsy of mass lesion, histopathological examination showed presence of thymic tumour.

PET CT suggestive of large fat density lesion with multiple patchy solid components arising from thymus. We did PET CT to rule out malignancy and metastasis

Patient underwent right posterolateral thoracotomy, large gray yellow to gray tan soft tissue was excised, weighing $2.7 \mathrm{~kg}$, measuring 28x24x8 cm was removed.

Fig. 6: Histopathological examination of surgical specimen (H \& E stain, x 20x magnification shows presence of normal thymic tissue with adipose tissue and presence of hassal corpuscles suggestive of thymolipoma Post-operative course was uneventful.

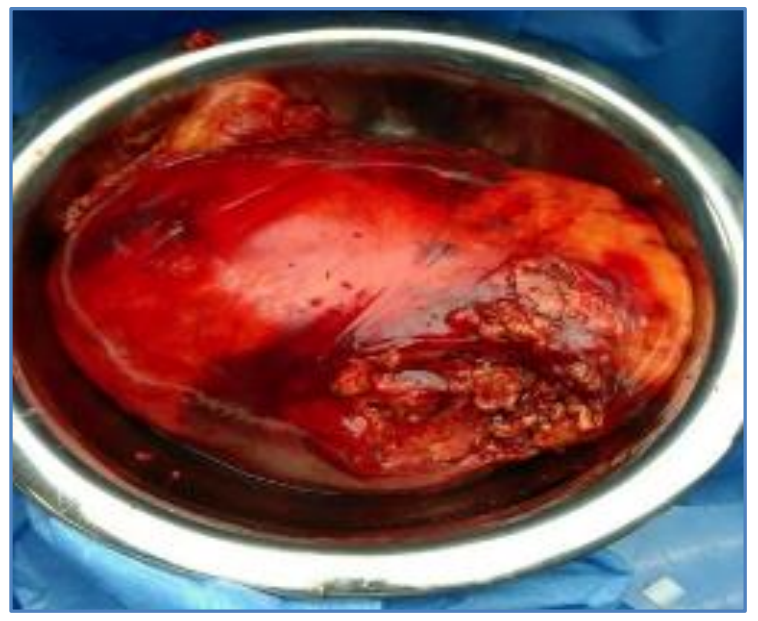

Fig. 5: Excised gross specimen

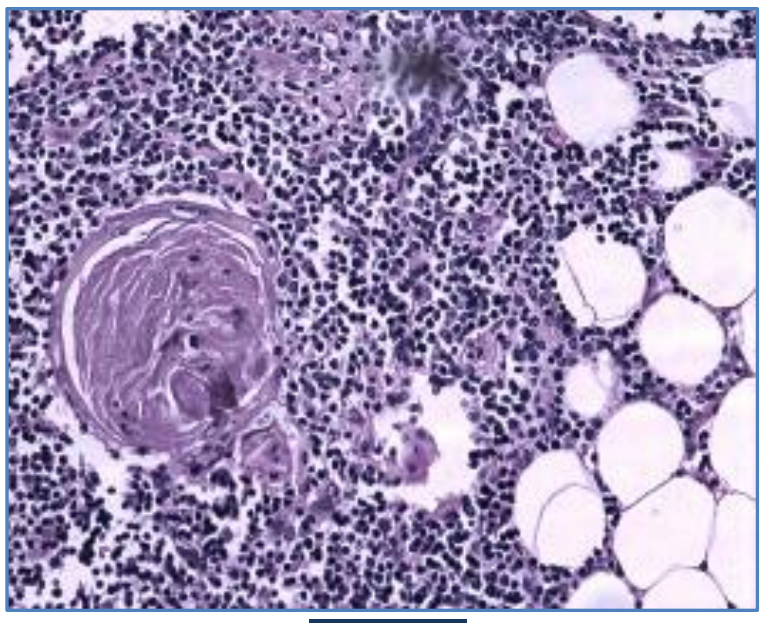

Fig. 6 
Fig. 7: Postoperative chest X-ray.

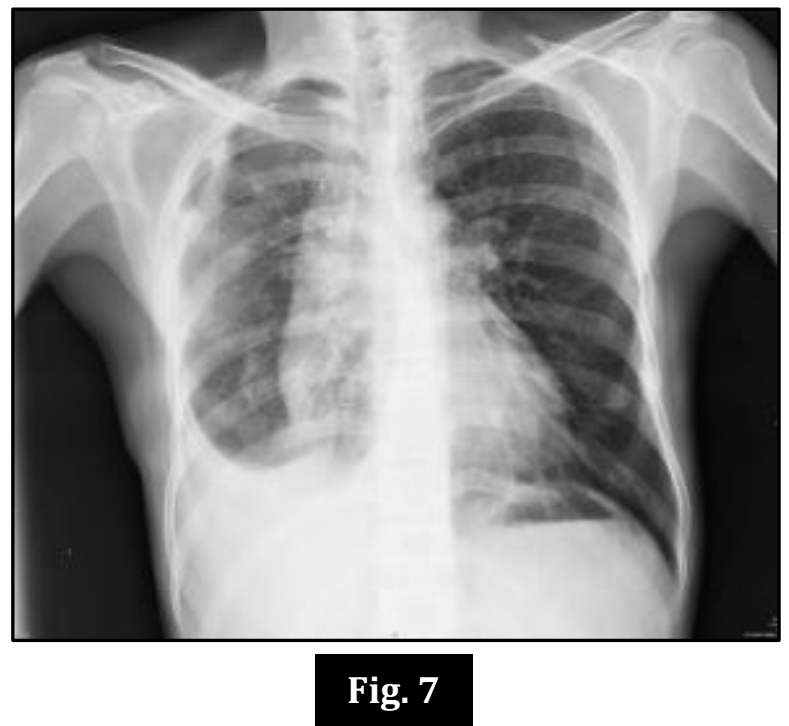

DISCUSSION: Thymolipoma is an uncommon benign neoplasm of thymus. There is no gender predilection and the patients' ages range from 3 years old to 76 years old.2,8, Incidence is approximately 0.12 cases per 100000 inhabitants per year. ${ }^{10}$ It is also known as lipoma of the thymus, benign thymoma, thymolipomatous hamartoma, lipothymoma, and mediastinal lipoma.

Arising in the anterior mediastinum at the level of the thymus gland, these soft and pliable tumors droop inferiorly as they enlarge and are said to slump onto the diaphragm, accommodating themselves to the spaces between the lungs and the heart, diaphragm, or anterior mediastinum. ${ }^{3}$

Pathogenesis of this tumour has not been clearly elucidated, four possible theories have been postulated. Briefly, the first suggests that thymolipomas are lipomas arising from within the thymus ${ }^{6}$. The second is that the thymus initially undergoes hyperplasia, the gland itself thereafter becoming replaced by fatty tissue. ${ }^{11}$ The third possibility (The 'mixed tumour' theory) suggests that both thymic and fatty tissue are neoplastic and contribute equally to the development of the thymolipoma. ${ }^{12}$ The fourth and final theory suggests that these tumours are a variant of thymomas, which undergo fatty degeneration. ${ }^{13}$

When the patient experiences symptoms, they are usually related to compression of adjacent structures, such as the heart, the great vessels, the lungs or the bronchi. ${ }^{14}$ Approximatly half of the patients with this tumor experience symptoms such as dyspnea, chest pain, and weight loss ${ }^{10}$. The frequency of the symptoms increases once the tumour increases in size. Our patient had cough, dysnea and chest pain.

On standard chest X-ray, the radiologic features can mimic several conditions such as cardiomegaly, pericardial effusion, and pericardial tumors. ${ }^{15}$ Differential diagnosis with large pleural tumor, basal atelectasis, and pulmonary sequestration is necessary. ${ }^{3}$ Chest skiagram of our case showed a large homogenous density lesion in right hemithorax. Characteristic CT findings involve fatty tissue containing soft tissue streaks that probably represent islands of normal thymic components. ${ }^{16}$ Fat density on CT scans, however, can also indicate lipoma, liposarcoma, teratoma, prominent epicardial fat pad or congenital diaphragmatic hernias. ${ }^{17}$ CT thorax study of our patient showed a lesion arising from thymus, with multiple areas of fat density suggestive of thymolipoma. 
In general, MRI scans show areas of high signal intensity intermingled with areas of intermediate intensity on T2-weighted images, and the adipose tissue of the tumor appears isointense in T1-weighted images. ${ }^{18}$ Although the diagnosis is strongly suggested by imaging studies that demonstrate fat and soft tissue within the tumor without the invasion of neighboring structures, it is not possible to make an exact diagnosis or even to differentiate benign from malignant neoplasms. ${ }^{19,20}$

So we proceeded with CT guided lung biopsy to confirm the diagnosis and to exclude other differential diagnosis. Microscopic features include the presence of normal adult adipose tissue with accumulation of lymphocytes and the characteristic scattered islands of Hassal's concentric corpuscles of thymic tissue. The amount of the latter is well in excess of that normally expected for the patient's age. ${ }^{21}$

The only curative treatment is surgical resection of the tumor, which can be accomplished via sternotomy, anterolateral thoracotomy, clamshell incision or sternotomy accompanied by anterolateral thoracotomy (Hemiclamshell incision). The choice must be individualized for each anatomical presentation of the neoplasm. ${ }^{22,23}$

CONCLUSION: Thymolipoma is a rare thymic neoplasm, mostly asymptomatic. Patients report to hospital usually once the tumour reaches large size. It should considered as a differential diagnosis if chest radiology is suggestive of anterior mediastinal mass.

Surgical resection is the treatment of choice. Prognosis is excellent.

\section{BIBLIOGRAPHY:}

1. Lange I. Uber ein lipom des thymus. Cited from Zentralbl Allg Pathol Anat 1916; 27: 97-100.

2. Mourad OM, Andrade FM, Abrahão P, Monnerat A, Judice LF. Asymptomatic giant mediastinal mass: a rare case of thymolipoma. J Bras Pneumol 2009; 35(10): 1049-52.

3. Teplick JG, Nedwich A, Haskin ME. Roentgenographic Features of thymolipoma. Am J Roentgenol Radium Ther Nucl Med 1973; 117: 873-80.

4. Mc Manus KG, Allen MS, Trastek VF. Lipothymoma with red cell aplasia, hypogammaglobinemia and lichen planus. Ann Thorac Surg. 1994; 58: 1534-6.

5. Yoshihiro K, Yokomori K, Ohkura M, Kataoka T, Narita M, Takemura T. Giant thymolipoma in a child. J Pediatr Surg 1993; 12: 1622-1625.

6. Dunn BH, Frkovick G. Lipomas of the thymus gland. Am J Pathol 1956; 32: 41-51.

7. Matsudaira N, Hirano $H$, Itou S, Matsuura K, Kanou M, Ogawa T. MR imaging of the thymolipoma. Magn Reson Imaging 1994; 24: 959-961.

8. Hirai S, Hamanaka Y, Mitsui N, Kumegai H, Kobayashi T. Gigantic thymolipoma. Jpn J Thorac Cardiovasc Surg 2002; 50: 40-2.

9. Nishimura O, Naito Y, Noguchi Y, Matsuoka S, Takanaka K. Thymolipoma: a report of three cases. Jpn J Surg 1990; 20: 234-7.

10. Gamondes JP, Balawi A, Greenland T. Seventeen years of surgical treatment of thymoma: factors influencing survival. Eur J Cardiothorac Surg. 1991; 5: 124-31.

11. Rubin M, Mishkin S. The relationship between mediastinal lipomas and the thymus. J Thorac Surg 1954; 27(5): 494-502.

12. Hall GFM. A case of thymolipoma with observations on a possible relationship to intrathoracic lipomata. Br J Surg 1948; 36: 321-324. 
13. Le Marc'hadour F, Pinel N, Pasquier B, Dieny A, Stoebner P, Couderc P. Thymolipoma in association with myasthenia gravis. Am J Surg Pathol 1991; 15: 802-809.

14. Ceran S, Tulek B, Sunam G, Suerdem M. Respiratory failure caused by giant thymolipoma. Ann Thorac Surg. 2008; 86(2): 661-3.

15. Gamanagatti S, Sharma R, Hatimota P, Guleria R, Arvind S. Giant thymolipoma. AJR Am J Roentgenol 2005; 185: 283-4.

16. Shields TW, Robinson PG. Mesenchymal tumors of the mediastinum. In: Shields TW, Lo Cicero J, Ponn RB, editors. General Thoracic Surgery, Vol. 2. 5ed. Philadelphia: Lippincott Williams \& Wilkins; 2000. p. 2357-423.

17. Faerber EN, Balsara RK, Schidlow DV, Marmon LM, Zaeri N. Thymolipoma: computed tomographic appearances. Pediatr Radiol. 1990; 20(3): 196-7.

18. Shirkhoda A, Chasen MH, Eftekhari F, Goldman AM, Decaro LF. MR imaging of mediastinal thymolipoma. J Comput Assist Tomogr. 1987; 11(2): 364-5.

19. Saad Jr R, Dorgan Neto V, Gonçalves R, Botter M, Siqueira LC. Mediastinal liposarcoma: a case report. J Bras Pneumol. 2008; 34(1): 55-8.

20. Mase T, Kawawaki N, Narumiya C, Aoyama T, Kato S, Nagata Y. Primary liposarcoma of the mediastinum. Jpn J Thorac Cardiovasc Surg. 2002; 50(6): 252-5.

21. Rosai J. Ackerman's surgical pathology. 8th ed. New York: Mosby; 1996. p. 463, 873-7.

22. Moran CA, Rosado-de-Christenson M, Suster S. Thymolipoma: clinicopathologic review of 33 cases. Mod Pathol. 1995; 8(7): 741-4.

23. Rosado-de-Christenson ML, Pugatch RD, Moran CA, Galobardes J. Wang Y, Sun Y, et al. Diagnosis, treatment and prognosis of thymoma: an analysis of 116 cases. Chin Med J (Engl). 2003; 116(8): 1187-90.

\section{AUTHORS:}

1. Premananth P.

2. Dhanasekar T.

3. Manu Kurian Baby

4. Periyasamy,

5. Rajagopalan B.

\section{PARTICULARS OF CONTRIBUTORS:}

1. Senior Resident, Department of Chest \& TB, Sri Ramachandra Medical College \& Research Institute.

2. Associate Professor, Department of Chest \& TB, Sri Ramachandra Medical College \& Research Institute.

3. Post Graduate, Department of Chest \& TB, Sri Ramachandra Medical College \& Research Institute.

FINANCIAL OR OTHER COMPETING INTERESTS: None
4. Professor, Department of Cardiothoracic \& Vascular Surgery, Sri Ramachandra Medical College \& Research Institute.

5. Professor, Department of Chest \& TB, Sri Ramachandra Medical College \& Research Institute.

\section{NAME ADDRESS EMAIL ID OF THE CORRESPONDING AUTHOR:}

Dr. Premananth $P$, 110-B Block,

Gents Hostel,

Sri Ramachandra University, Porur, Chennai-600116.

E-mail: premananth86@yahoo.com

Date of Submission: 29/06/2015.

Date of Peer Review: 30/06/2015.

Date of Acceptance: 20/07/2015.

Date of Publishing: 27/07/2015. 